\title{
The Errant Space - The Reshaping of Place through the Visualisation of Ambient Environmental Audio
}

\author{
Alan Dunning \\ University of Calgary \\ 2500 University Dr. NW, Calgary, AB T \\ Canada \\ adunnning@ucalgary.ca
}

\begin{abstract}
This paper explores issues contained within the works comprising the Errant Space - First Words cycle of installations. It does so within the contexts of pattern recognition, and notions of what might constitute a digital uncanny. Investigations have focused on the exploration of the momentary perception that there is something meaningful arising from a place where there should properly be nothing meaningful.
\end{abstract}

Pattern recognition. Randomness. Presence and absence. Digital uncanny. New media.

\section{ERRANT SPACE - FIRST WORDS}

The series of works in the Errant Space - First Words series sets out to consider our everchanging relationship to built space by analysing ambient audio environments and presenting the results as artworks. It does so that an observer/listener might see and occupy enclosing space differently, by using pattern and speech recognition to encourage an exploration of its immaterial, psychic shape.

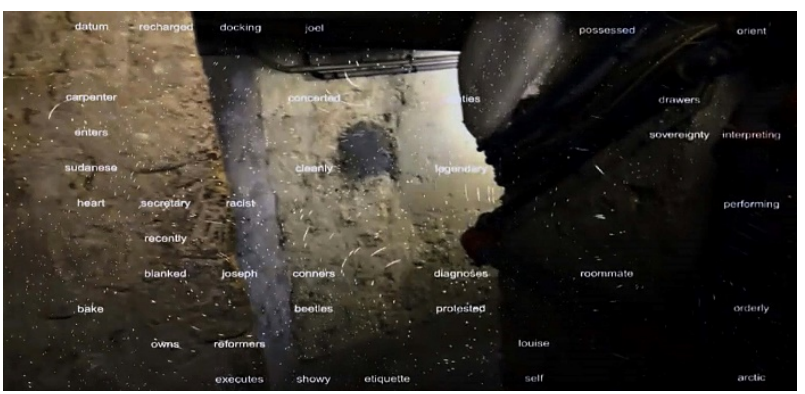

Figure 1: École des mines, installation, Paris, 2016

As part of a larger exploration into the digital uncanny, the Errant Space series uses the deficiencies of speech recognition systems to generate word clusters and sounds from ambient noise that re-contextualise the space in which they are presented. With no clear plot or narrative arc the works rely on the feedback between a contextualised and contextualising space defined and defining through historical and cultural understanding, and the simultaneous redefinition of place that occurs through the authority of the analytic process itself, and the words that are generated. What should be a meaningless babble of words and sounds stubbornly asserts itself to suggest pattern, presence and meaning in the face of a system that is observably random and chaotic, as a viewer involuntarily identifies or constructs patterns in the flow of experience.

The works use speech recognition programmes to tease sounds and phrases from environments in which there is no apparent speech heard, or so noisy as for speech to be indistinct, to populate a space with poetic fragments suggestive of various intelligent speakers. The intent is to change the nature of a space to encourage the perception of the most ordinary objects as poetically exciting, uncanny, and even supernatural.

George Wolford at Dartmouth College finds that people find patterns in random sequences, even when they are told that the sequences are random. "There appears to be a module in the left hemisphere of the brain that drives humans to search for patterns and to see causal relationships ...even when none exist." (Wolford 2000). 
His research partner, Michael Gazzaniga (2009), has nicknamed this creative narrative generating part of the brain "the interpreter."

What Wolford and Gazzaniga are suggesting is that we are driven to find pattern in randomness, that it is unavoidable, even when we are aware of the drive itself. Errant Space uses this tendency to relocate presence in an architectural field.

\section{PATTERN RECOGNITION}

Artworks over the last decade have used this interpretative drive to explore ambient environmental audio as means to generate sounds and images that can invoke recent and distant histories or invisible elements, and to create psychologically charged sites. In all of these, the site itself is monitored and analysed using audio, speech and pattern recognition software to produce strings of images, sounds and texts, that build a narrative linked directly to the site through perceptions of a participating audience.

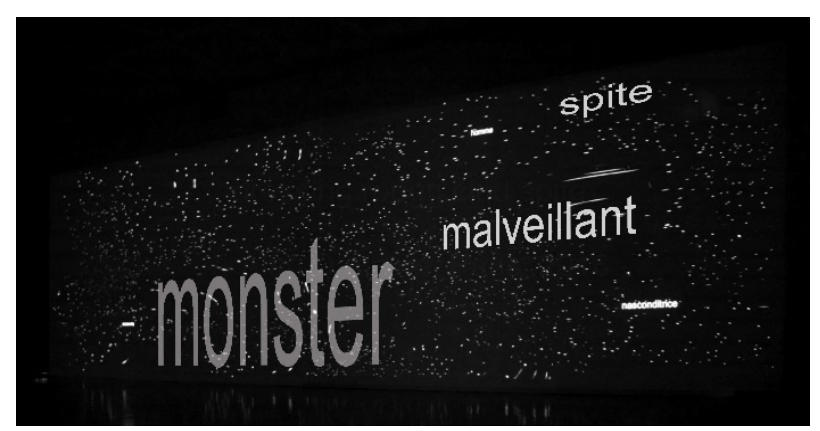

Figure 2: First Words, installation, Paris, 2016

First Words (2014-2017) is a whole room projection and sound installation. The work uses bespoke speech recognition software to tease words, phrases and sounds from our sonic environment, and projects these extremely rapidly, both as sound and vision, into the space. Microphones monitor a space or location, computers process the audio, words are spoken and broadcast into the space and projected as images onto the walls of the gallery. Ambient noise, both above and below the threshold of human perception, is analysed using custom speech recognition software to reveal unbidden sound and speech. The results, fragments of sound, human speech, and buzzing, sound like nonsense, like gibberish, but are often disturbingly suggestive of meaning and usually exhibit authentic grammatical structure. The words and phrases that emerge are often convincingly real, suggesting some actual voice or intelligence behind the words, though, however unsettling, actually they emerge only from algorithms carrying out the work of analysing the audio, and the imagination of the listener.
The project exploits speech recognition software's tendency to throw up false positives, to generate clusters of words, phrases and sounds and uses them in meaningful artistic ways to introduce new narratives that re-describe and reshape space by changing how we feel about a location. It draws attention to how we might perceive space differently through the lenses of the misheard and the half-heard to perceive alternative realities. Evoking Electronic Voice Phenomena - the uncertain parapsychological finding of unbidden voices in recorded electronic noise - and the uncanny transmissions of numbers stations - those radio broadcast of indecipherable strings of spoken numbers and text, and fragments of music - the project exploits the deficiencies of speech recognition software, to generate new emotional responses.

Meaning is always generated through relations between place, context and participant. (Hatch 1992) It is both temporary and enduring, dynamic and stable, comprising many psychological, biological and emotional states, and systems of belief, and it is easily and continuously remade. Whether real or imagined meaning is bound to context even as context is bound to meaning.

The works in the Errant Space cycle are in many ways generative systems. Words are invented as much, if not more than discovered. Noises received by microphones distributed throughout a space send signals to a computer that looks for and finds instances of speech. What it actually flags are false positives that have no actual relation to a real world utterance. They have no indexical relation to an uttering body. They are not sounds of people, but another kind of sound, loaded with potential meaning, which arises accidentally, but irresistibly, from the hybrid interaction between machine and body. The work uses a machine pareidolia - the perception of images or sounds in random stimuli to generate a human apophenia - the tendency to perceive meaningful patterns within random data.

To all intent and purposes when these strings of words look like speech, they are accepted as speech. That such unrelated words resolve themselves into meaningful sentences, however fragmentary, without conscious effort, and that they remain even so when attending closely to them, suggests that it is paradoxically their lack of objective meaning that generates their form. It is the very ambiguity and indeterminacy of the sense of something that allows the brain to reconfigure them as indexical, and to do so in the contextualising field of their location. 


\section{UNCERTAINTY}

A similar effect, albeit one based in vision, can be seen in Michelangelo Antonioni's film Blow-Up (1966). The main protagonist, Thomas, a photographer, takes some pictures of a couple's meeting in Maryon Park, in Greenwich. When developed, the negatives reveal what seems to be evidence of a murder. Subsequent enlargements reveal what might be a body and a gun.

Jonathon Dawson (2006), in "Blow-Up, Senses of Cinema" writes that the photographer "... sees something (or maybe not) while photographing in a London park. The swinging world recedes as Thomas becomes morbidly obsessed by the possibility he has in fact photographed a murder. Is that a body under the bushes? If not, what, then? The title's meaning becomes clear as Thomas repeatedly enlarges, studies, and reworks his negatives to locate the proof for something, any evidence of a possible occurrence that seems, as his obsession grows, to become increasingly elusive. Subsequently, the film becomes, in part, a meditation on the very nature of reality and how we deform the natural with interpretations and inflexions....any observed happening (however neutral or scientific the act of observation) is altered by the mere presence of the observer. Observation is thus never a neutral or abstract process. Certainly if there is a central informing principle to the narrative matrix of Blow-Up it is this: that no phenomenon is pure unto itself - especially when human emotions come into play, let alone consideration like guilt, obsession and, finally, fear." The black and white prints, enlarged until they show only blobs of silver particles are surely unintelligible. And yet they are obstinately open to interpretation. What do the photographs show - an innocent meeting, the scene of a murder, or are they merely an opportunity for one or more pareidolic experiences? Cultural and biological compulsions and interpretations drive these random optical marks into patterns that demand to be recognised - and in turn more and more believed. A recursive loop forms - the more believable the images are the more they look like the subject's desires, and in the desiring the more believable they become.

In Anatomy of a Murder: Bazin, Barthes, Blow-Up, Asbjørn Grønstad (2004), explains: "Antonioni brings to the surface that tantalising semiotic opacity of which all of the visual arts partake but which so infrequently gets articulated. What is more, the film flaunts the contingencies of visual hermeneutics, it emphasises the inter-relations of photography, corporeality, decomposition, and death, and, most obviously, it configures the instability, the limits, of photography's truth. The complex presence of the film's corpse pinpoints this perennial interpretive dilemma: we are certain that we see it, but we cannot be certain that what we see is real."

Ambiguity invites multiple interpretations. The construction of our world arises out of the feedback between our sensations and our perception of the external world. This construction is dynamic - as we acquire new information, our sensations and then our perceptions change, suggesting that perception, like Antonioni's photographer discovered, might just be another sensation, rooted in belief.

Film and cultural theorist Siegfried Kracauer (1960) in discussing the reality of the street and its effect on the flâneur continues the discussion: ... an incessant flow of possibilities and near-intangible meanings appears. This flow casts its spell over the flâneur or even creates him. The flâneur is intoxicated with life in the street - life eternally dissolving the patterns which it is about to form.

In turn, this recalls neuroscientist Antonio Damasio's (2009) idea of the dispositional self that he describes as, "an evanescent reference state, so continuously and consistently reconstructed that the owner never knows that it is being remade unless something goes wrong with the remaking. Present continuously becomes past, and by the time we take stock of it we are in another present, consumed with planning for the future, which we do on the stepping stones of the past. The present is never here."

Taken together with the contextual social framing that defines every place and Gazaniga's interpreter, Damasio's dispositional self might suggest that the construction of meaning in the Errant Space works is not only continuous and dynamic, but also, as meaning is revealed and as patterns are irresistibly recognised, epiphanic.

In Praise of Nonsense: Aesthetics, Uncertainty, and Postmodern Identity, Ted Hiebert (2012) says "... one must mistake the experience of apophenia for one of epiphany - mistake hallucinations for realisations- even though one knows it is a mistake to do so. At the same time, one must not exit the dynamic of error which allows for the perpetuation of apophenia from a structural perspective and of epiphany from an embedded perspective - a selfdeception is required for the perpetuation of falsity and erroneous being. What emerges is a paradoxical logic, in that one must distrust one's own suspended disbelief while at the same time suspending belief in one's distrust." 


\section{THE REVEAL}

Freud suggested that the uncanny might arise from feelings that are normally hidden or unspeakable.

"...the specificity of the sensation of the uncanny lies in the fact that something is frightening, not because it is unfamiliar or new, but because what used to be familiar has somehow become strange. (Freud) ...quotes a phrase by Schelling which formulates precisely this relation: "unheimlich is that what ought to have remained hidden, but has nonetheless come to light" (Masschelein 2003).

The works seek to use this experience of something made strange, through something hidden being revealed, to complicate a disturbance in the relational field made of the self and its surrounding space. As a participant listens to and reads the texts emerging from the speech recognition analysis, the results, fragments of sound and speech, expected to be random gibberish, are perceived as meaningful and structured. Reconfigured through the lens of the uncanny, the familiar space, the undifferentiated speech, like Antonioni's photographs, is remade in a participant's belief's and desires.

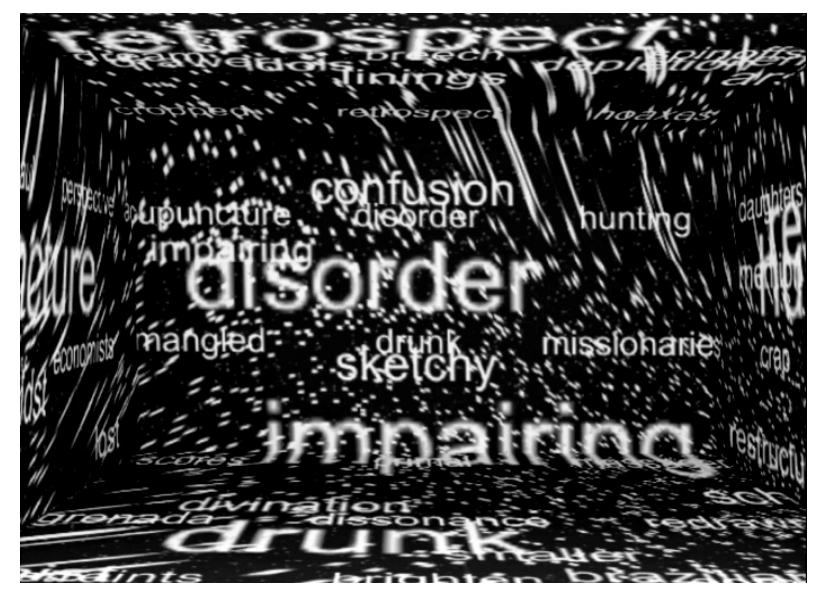

Figure 3: First Words, Last Acts, installation, 2016

The works in Errant Space encourages us to find the signal in the noise, and its generated words and phrases the work provide a rich atmosphere that demands interpretation. However, because of the ways at which texts and words are generated and broadcast while we are certain that we hear something, that we read something, we are unsure as to what has been heard and read, and moreover what, if anything, each might mean. Meaning is withheld, is beyond our understanding, and is disturbingly in conflict with our desires to recognise order. Nonetheless, the audience is primed to respond in particular ways. Visualising and sonifying sound in an art context presents a listener with an experience that is familiar - it is at once an artwork that expects interpretation, it is cinematic and fictive, and it is further contextualised through a computing science mechanism of analysis and pattern recognition.

Despite its apparent randomness, there is a sense that this is a system of logic, reinforced by how they are displayed and produced. False positives abound in the analysis, but what is perceived is that something is actually emerging from the data that is generated directly from the analysis, even when the meaning remains uncertain. In this way, the texts are a visibly direct function of the space suggesting that something is being discovered, that something is being revealed - that something in the material of the space is at play in the generation of the texts.

\section{THE STONE TAPE}

In 1972 BBC television broadcast a Nigel Kneale play called The Stone Tape. In it a team of scientists examine a ghostly event in an old building. They discover the possibility of the stones being a kind of recording medium for images and events that can be played back if given a powerful enough stimulus, and that the recording is rather than broadcast, perceived in the mind.

\footnotetext{
"It must work like ... a recording. Fixed in the floor and the walls, right in the substance of them. A trace ... of what happened in there. And we pick it up. We act as detectors - decoders amplifiers." (Kneale 1972).
}

Errant Space uses The Stone Tape as a fictional device to engage with theory about the material of the city and its capacity to store evidence of past lives and events. While the Stone Tape theory has been adopted by paranormal investigators to explore hauntings and other phenomena, the works in Errant Space use this as a purely fictive, but perhaps persuasive, device to engage with the idea that space is marked through index that can point to place as a function of the accretion of social and cultural sediment and that its revelation can invoke the uncanny. Marks in stone, polished edges, worn stairs, all index the passage of bodies in time, that lead to the reconstruction of a space beyond its immediate architectural limits, making it easy to imagine invisible and past events and and personae.

The works call attention to the way that spaces have been and are being inhabited. The triggers for such imaginings are indexical, that is, words connect to bodies, speech connects to utterance. It is obvious that the texts are generated somewhat randomly by computational analysis, but meaning imagined problematises the source, and invokes the uncanny. The mere suggestion that these texts are generated from something other than a machine poeticises space in such a way as to open it up to new inspection and to new relationships. 
The works produce word fragments from ambient audio that does not have an obvious speech component. Simple speech recognition software identifies, words and phrases, and speaks these into a space using text to speech software, and projects the texts directly on a wall. Texts and speech appear and disappear very rapidly in a confusion of images and sounds. They are presented just slowly enough to read, but quickly enough to wonder if the word was seen or heard at all. The sounds and texts generated are part of a feedback loop between place, inhabitant and context, that produces an environment in constant, though temporary, flux. In the end, the works explore ideas about how various positive or negative emotional valence affects space and changes the shape of space, by changing how it is perceived and, consequently, how it is occupied.

The visualisation and sonification of speech elements in noise sets out to develop works that suggest different ways to experience the world. That is, by analysing our bodies and environments to reveal concealed, hidden, or unbidden, information, that disturbs our given or received sense of ourselves and our surroundings. In exploring the world using sound to reveal the invisible, invisibility has become a theory of sight, and noise the heart of the signal.

\section{REFERENCES}

Antonioni, M. (1966) Blow-Up, Chapel Films, London.

Damasio, A. (1994) Descartes Error. Avon Books, New York.
Dawson, J. (2005) Blowup. Senses of Cinema, January. Cinémathèque Annotations on Film, \# 34, http://sensesofcinema.com/contents/cteq/05/34/blo wup.html (retrieved 1 May 2017).

Gazzaniga, M. (2009) The Split Brain Revisited. Scientific American, July, p. 29.

Grønstad, A. (2004) Anatomy of a Murder: Bazin, Barthes, Blow-Up. Film Journal, 9.

Hatch, E. (1992) Discourse and Language Education. Cambridge University Press, Cambridge.

Hiebert T. (2012) In Praise of Nonsense: Aesthetics, Uncertainty, and Postmodern Identity. McGill-Queen's University Press (MQUP), Montreal, Canada.

Kneale, N. (1972) The Stone Tape. Producer: Lloyd, I. Director: Sasdy, P. Produced on BBC Television, 25 December.

Kracauer, S. (2006) Theory of Film: The Redemption of Physical Reality. Oxford University Press, Oxford.

Masschelein, A. (2003) A Homeless Concept. Shapes of the Uncanny in Twentieth-Century Theory and Culture, Image and Narrative. http://www.imageandnarrative.be/inarchive/uncann y/anneleenmasschelein.htm (retrieved December 2016).

Wolford, G. et al. (2000) The Left Hemisphere's Role in Hypothesis Formation. Journal of Neuroscience, 20 RC64, pp. 1-4. Washington. 